\title{
Soğutma Sisteminde R404A Yerine R454C Soğutucu Akışkanın Kullanılmasının İncelenmesi: Enerji ve Çevresel Analizi
}

\author{
Ragıp YILDIRIM*1, Kazım KUMAŞ ${ }^{1}$, Ali Özhan AKYÜZ², \\ ${ }^{1}$ Burdur Mehmet Akif Ersoy Üniversitesi, Bucak Emin Gülmez Teknik Bilimler Meslek Yüksekokulu, Elektrik ve \\ Enerji Bölümü, 15300, Burdur, Türkiye \\ ${ }^{2}$ Burdur Mehmet Akif Ersoy Üniversitesi, Bucak Emin Gülmez Teknik Bilimler Meslek Yüksekokulu, Elektronik ve \\ Otomasyon Bölümü, 15300, Burdur, Türkiye
}

(Alınış / Received: 11.06.2021, Kabul / Accepted: 12.07.2021)

Araştırma Makalesi

Anahtar Kelimeler

Sera gazları,

Soğutucu akışkanlar,

Enerji analizi,

LCCP
Özet: GWP oranı düşük soğutucu akışkanlar soğutma sistemlerinin karbon ayak izinin azaltılması için önemlidir. Bu çalışmada bir soğutma sisteminde R404A ve alternatifi olan R454C soğutucu akışkanlarının enerji ve çevresel analizi yapılmıştır. Analizler 5 farklı evaporatör sıcaklığı $\left(-15^{\circ} \mathrm{C}\right.$ ile $\left.+5^{\circ} \mathrm{C}\right)$ ve bir kondenser sıcaklığı (35 ${ }^{\circ} \mathrm{C}$ ) için yapılmıștır. R454C'nin COP değeri R404A'dan yaklaşık olarak \% 4.0 oranında daha yüksektir. R454C'nin LCCP değeri R404A'dan biraz düşüktür (yaklaşık \%3.5). Soğutma sistemlerinin karbon ayak izinin azaltılmasında soğutucu akışkanların GWP oranının düşük olması tek başına çözüm değildir. Soğutma sistemlerinin toplam karbon ayak izinin azaltılması için soğutma sistemi veriminin arttırılması ve çevre dostu enerji kaynaklarının (rüzgar, güneş, jeotermal enerji kaynakları vd.) kullanılması gerekir.

\section{Investigation of Using R454C Refrigerant Instead of R404A in a Refrigeration System: Energy and Environmental Analysis}

\section{Keywords}

Greenhouse gases,

Refrigerants,

Energy analysis, LCCP

\begin{abstract}
Low GWP refrigerants are important for reducing the carbon footprint of cooling systems. In this study, energy and environmental analysis of R404A and its alternative $\mathrm{R} 454 \mathrm{C}$ refrigerants in a refrigeration system were made. Analyzes were made for 5 different evaporator temperatures $\left(-15{ }^{\circ} \mathrm{C}\right.$ to $\left.+5{ }^{\circ} \mathrm{C}\right)$ and a condenser temperature $\left(35^{\circ} \mathrm{C}\right)$. R454C has a COP of approximately $4.0 \%$ higher than $\mathrm{R} 404 \mathrm{~A}$. The LCCP of R454C is slightly lower than R404A (approximately 3.5\%). A low GWP ratio of refrigerants is not the only solution in reducing the carbon footprint of cooling systems. Low GWP ratio of refrigerants is not the only solution in reducing the carbon footprint of cooling systems. In order to reduce the total carbon footprint of cooling systems, it is necessary to increase the efficiency of the cooling system and use environmentally friendly energy sources (wind, solar, geothermal energy sources, etc.).
\end{abstract}

\section{Giriş}

Soğutma ve isıtma sistemlerinin toplam karbon ayak izinin azaltılması için çeşitli yasal düzenlemler yapılmıştır. Bu kapsamda küresesel ısınma potansiyeli (GWP) yüksek olan soğutucu akışkanların kullanımının ve üretiminin azaltılması gerekmektedir. Örneğin, Avrupa birliğinde F-gazı yönetmeliğ (CE $842 / 2006$ ) ve 2014 yılındaki F-gazı yönetmeliğindeki (N 517/2014) değișiklik ile isıtma, havalandırma, iklimlendirme ve soğutma (HVAC-R: Heating, Ventilation, Air conditioning and Refrigerating) sistemlerinde kullanılan soğutucu akışkanlara kısıtlamlar getirmiştir [1]. Buhar sıkıștırmalı sistemlerin karbon ayak izinin azaltılmasında GWP oranı düşük soğutucu akışkanlar kullanmak tek başına yeterli değildir. $\mathrm{Bu}$ yüzden buhar sıkıștırmalı sistemlerinin enerji verimliliği arttırılmalı ve yenilenebilir enerji kaynaklaklarının kullanılması gerekir. 
Teknolojinin gelişmesiyle birlikte soğutma sistemleri yaygın bir şekilde kullanılmaktadır. R404A soğutucu akışkanı soğutma sistemlerinde yaygın bir şekilde kullanılan soğutucu akışkanlardan birisidir. R404A soğutucu akışkanın ozon delme potansiyeli sıfırdır ancak GWP oranı yüksektir (3943)[2]. Soğutucu akışkanların küresel ısınma üzerindeki etkileri azaltmak için bilim insanları GWP oranı düşük alternatif soğutucu akışkanlara ve soğutucu akışkan şarj miktarını azaltacak sistemlere odaklanmışlardır [3]. R404A'ya alternatif soğutucu akışkanlardan biriside R454C'dir. R404A ve R454C'nin karakteristik özellikleri Tablo 1'de verilmiștir.

Tablo 1. R404A ve R454C'nin özellikleri [2]

\begin{tabular}{lcc}
\hline & R404A & R454C \\
\hline $\begin{array}{l}\text { Karıșım oranı } \\
\begin{array}{l}\% \quad \text { kütlesel } \\
\text { olarak) }\end{array}\end{array}$ & $\begin{array}{c}\text { R125/R143a/R134a } \\
(44 / 52 / 8)\end{array}$ & $\begin{array}{c}\text { R32/R1234yf } \\
(21.5 / 78.5)\end{array}$ \\
\hline $\begin{array}{l}\text { Kaynama } \\
\text { noktası ( }{ }^{\circ} \text { ) }\end{array}$ & -46.20 & -45.60 \\
\hline $\begin{array}{l}\text { Kritik sıcaklık } \\
\text { (oC) }\end{array}$ & 72.00 & 85.70 \\
\hline $\begin{array}{l}\text { Kritik basınç } \\
\text { (bar) }\end{array}$ & 37.20 & 43.20 \\
\hline $\begin{array}{l}\text { Küresel } \\
\text { Isınma } \\
\text { potansiyeli } \\
\text { (GWP) }\end{array}$ & 3943 & 146 \\
\hline ODP & 0 & 0 \\
\hline Güvenlik sınıf & $\mathrm{A} 1$ & $\mathrm{~A} 2 \mathrm{~L}$ \\
\hline
\end{tabular}

Mendoza-Miranda vd. [4], yaptıkları çalışmada, modifiye mikro kanatlı evaporatör modelinde R404A ve R134a'nın yerine kullanılabilecek R448A ve R450A iş akışkanlarının soğutma sistemlerindeki performansını incelemişlerdir. Oluşturulan modelin doğruluğu farklı çalışma şartlarında deneysel çalışmalar ile test ederek karşılaştırmıştır. Sonuç olarak R450A ve R404A soğutucu akışkanların daha uygun olduğunu ifade etmişlerdir. Li [5], yaptığı çalışmada R404A akışkanının yerine kullanılabilecek R452A akışkanın performansını değerlendirmiştir. R452A'nın R404A ile karşılaștırıldığında düşük ve orta buharlaşma sıcaklıklarında \% 5-15 arasında sera gazı emisyonunu azalttığını ifade etmiştir. Llopis vd. [2] yaptıkları çalışmada, R404A'nın alternatifi olarak kullanılabilecek daha düşük GWP değerine sahip R454C, R459B, R457A ve R455A soğutucu akışkanların enerji performansını deneysel olarak incelemișlerdir. R454C, R459B, R457A, R455A'nın R404'a göre enerji tüketimleri sirasıla \%2.45, \%11.55, \%10.69, \% 2.9 oranında daha düşük olduğunu belirtmişlerdir. Kumaş ve Akyüz [6] çalışmalarında R450A ve R134a akışkanlarının enerji parametreleri analiz etmişlerdir. R134a'nın R450A'dan daha yüksek COP değerine sahip olduğunu belirtmişlerdir.

$\mathrm{Bu}$ çalışmada, soğutma sisteminde R404A ve alternatifi olan düşük GWP oranına sahip soğutucu akışkan R454C teorik olarak incelenmiştir. Çalışmada soğutucu akışkanların enerji ve çevresel etki analizi yapılmış ve karşılaştırılmıştır.

\section{Materyal ve Metot}

Soğutucu akışkanların performanslarının değerlendirilmesinde tek kademeli buhar sıkıștırmalı soğutma çevrimi kullanılmıştır. Tek kademeli soğutma çevriminin şematik görünümü Şekil 1 de verilmiştir.

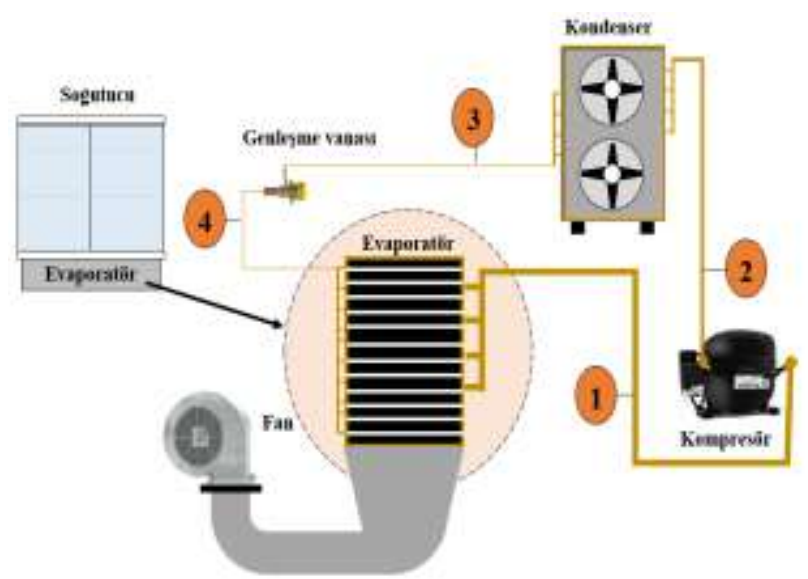

Şekil 1. Buhar sıkıștırmalı soğutma çevrimi

\subsection{Enerji analizi}

R404A ve R454C soğutucu akışkanların enerji analizi termodinamiğin birinci yasasına göre yapılmıştır. Buna göre Şekil 1'de verilen tek kademeli soğutma sistemi bileşenlerinin enerji denge denklemleri aşağıda verilmiştir [7], [8]:

Evaporatör:

$$
\dot{\mathrm{Q}}_{\text {evap. }}=\dot{\mathrm{m}}_{\mathrm{R}}\left(\mathrm{h}_{1}-\mathrm{h}_{4}\right)
$$

Kondenser:

$$
\dot{\mathrm{Q}}_{\mathrm{kond} .}=\dot{\mathrm{m}}_{\mathrm{R}}\left(\mathrm{h}_{2}-\mathrm{h}_{3}\right)
$$

Kompresör:

$$
\dot{\mathrm{Q}}_{\mathrm{komp} .}=\dot{\mathrm{m}}_{\mathrm{R}}\left(\mathrm{h}_{2}-\mathrm{h}_{1}\right)
$$

Genleşme vanası:

$$
\mathrm{h}_{3}=\mathrm{h}_{4}
$$

Soğutma sistemin enerji performans katsayısı:

$$
\text { COP }=\frac{\dot{\mathrm{Q}}_{\text {evap. }}}{\dot{\mathrm{W}}_{\text {komp. }}}
$$

Yukarıda verilen Eşitliklerde $\mathrm{h}$ ilgili referans noktasının entalpi değerini $(\mathrm{kJ} / \mathrm{kg})$ ve $\dot{\mathrm{m}}_{\mathrm{R}}$ soğutucu akışkan kütlesel debisini (kg/s) göstermektedir.

Teorik analiz yapılırken yapılan kabuller şunlardır:

- Soğutma kapasitesi(kW) : : 1 
- Kompresör izantropik verimi : 0.70

- Evaporatör sicaklığı $\left({ }^{\circ} \mathrm{C}\right) \quad$ : -15 ile 5

- Kondenser sicaklı̆̆l $\left({ }^{\circ} \mathrm{C}\right) \quad: 35$

- Așırı kızdırma sıcaklı̆̆ı $\left({ }^{\circ} \mathrm{C}\right) \quad$ : 5

- Aşırı soğutma sıcaklığı $\left({ }^{\circ} \mathrm{C}\right) \quad$ : 5

\section{2. Çevresel analiz}

Soğutucu akışkanların çevresel analizleri "Yaşam Döngüsü İklim Performansı (Life Cycle Climate Performance (LCCP)" yöntemine göre yapılmıștır. Yaşam Döngüsü İklim Performansı analizinde bir sistemin ömrü boyunca tüm emisyonları hesaplamaya dahil edilir (üretiminden bertaraf edilmesine kadar). Şekil 2'de görüldüğü gibi LCCP iki ana kategoriden oluşur: (I) doğudan emisyonlar ve (II) dolaylı emisyonlar[9]-[12].
Doğrudan emisyonlar, ünitenin kullanım ömrü boyunca atmosfere salınan soğutucunun etkilerinden oluşur (sızıntılardan kaynaklanan yıllık soğutucu kaybı, ünitenin kullanım ömrü sonunda soğutucu akışkan kaybı, atmosferdeki soğutucu akışkanın parçalanmasından kaynaklanan atmosferik reaksiyon ürünleri vb.). Dolaylı emisyonlar, ünitenin ömrü boyunca kullanılmasından kaynaklanan emisyonları içerir. (elektrik üretiminden kaynaklanan emisyonlar, malzeme üretiminde kaynaklanan emisyonlar, soğutucu akışkanların üretiminden kaynaklanan emisyonlar ve ünitenin kullanım ömrü sonrası geri dönüşümünden kaynaklanan emisyonlar) [9]-[11].

\section{LCCP = Doğrudan Emisyonlar + Dolaylı Emisyonlar}
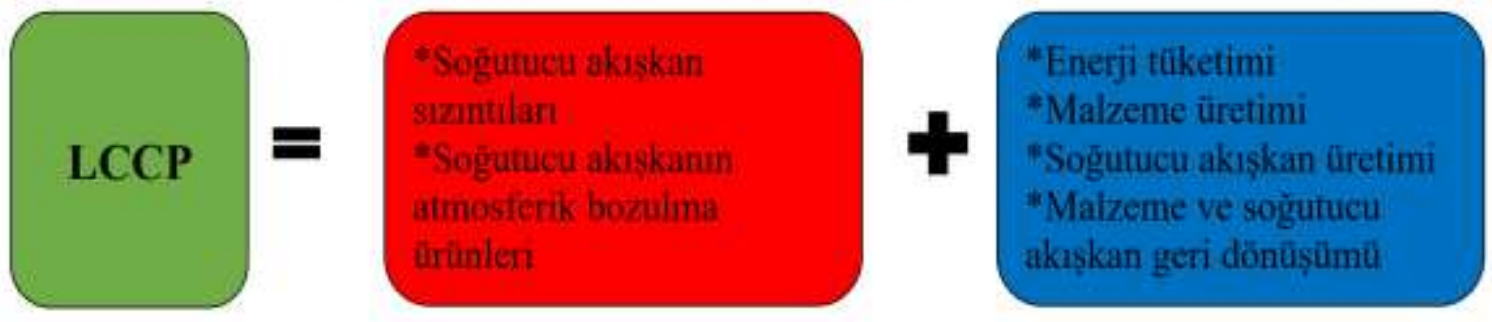

Şekil 2. LCCP kategorileri

Literatürdeki çalıșmaları incelediğimizde, buhar sıkıştırmalı sistemlerin LCCP emisyonların yaklaşık $\% 80$ ile \%95 i dolaylı emisyonlardan oluştuğu görülmüştür. Ve bu dolaylı emisyonların büyük bir çoğunluğu enerji tüketiminden kaynaklanmaktadır [10]-[12]. Dolayısıyla bu çalışmada LCCP analizinde enerji tüketiminden kaynaklanan emisyonlar hesaplanmıștır. Enerji tüketiminden kaynaklanan emisyonlar aşağıda verilen Eşitlik ile hesaplanır [10]:

$$
\mathrm{LCCP}=\mathrm{L} \times \mathrm{AEC} \times \mathrm{EM}
$$

Burada L, cihazın ömrünü (yıl), AEC yıllık enerji tüketimini (kWh/yr) ve EM elektrik üretimi emisyon değerini göstermektedir $\left(\mathrm{kgCO}_{2} / \mathrm{kWh}\right)$.

Tablo 2. LCCP analizi için kabuller

\begin{tabular}{ll}
\hline Soğutma kapasitesi(kW) & 1 \\
\hline $\mathrm{L}(\mathrm{yll})$ & 15 \\
\hline $\mathrm{EM}\left(\mathrm{kgCO}_{2} / \mathrm{kWh}\right)$ & $0.523[13]$ \\
\hline
\end{tabular}

\section{Bulgular}

\subsection{Enerji analiz sonuçları}

Yapılan teorik enerji analizinde soğutucu akışkanların debileri, kompresör enerji tüketimleri ve enerji performansları (COP) incelenmiş ve karşılaştırılmıştır.

Soğutma sisteminde soğutucu akışkanın debisi birçok parametreye bağlı olarak değişir (soğutucu akışkanın yoğunluğu, kompresörün izantropik verimi, kompresörün geometrik yapısı vb.). Soğutma Sisteminde R404A ve R454C kullanılması durumunda soğutucu akıșkan debisinin evaporatör sıcaklığına bağlı olarak değişimi Şekil 3'te görülmektedir. R404A'nın soğutucu akışkan debisi $8.1 \mathrm{~g} / \mathrm{s}$ ile $7.4 \mathrm{~g} / \mathrm{s}$ arasında değişirken, R454C'nin soğutucu akışkan debisi $6.5 \mathrm{~g} / \mathrm{s}$ ile $6.0 \mathrm{~g} / \mathrm{s}$ arasında değişmektedir. Şekil 3'te görüldüğü gibi R404A'nın soğutucu akıșkan debisi R454C den yüksek olduğu açlkça görülmektedir. Bunun nedeni R404A'nın yoğunluğu R454C'den yüksek olmasından dolayıdır.

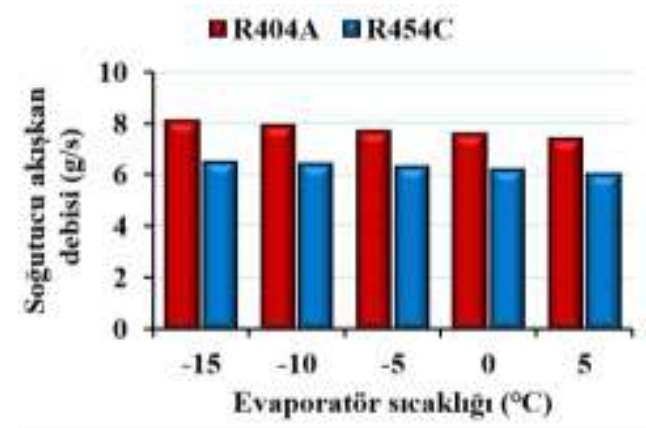

Şekil 3. Soğutucu akışkanların debisinin karşılaştırılması

Soğutma sistemin kompresör enerji tüketimi soğutma sisteminin enerji performansını (COP) önemli derecede etkiler. Soğutma Sisteminde R404A ve R454C kullanılması durumunda kompresör enerji tüketiminin evaporatör sıcaklığına bağlı olarak 
değişimi Şekil 4'te görülmektedir. R454A'nın kompresör enerji tüketimi $360 \mathrm{~W}$ ile $180 \mathrm{~W}$ arasında değişmektedir. R454C'nin kompresör enerji tüketimi $350 \mathrm{~W}$ ile $180 \mathrm{~W}$ arasında değişmektedir. R404A'nın kompresör enerji tüketimi R454C'den \%2.8 ile \%4.5 oranında daha yüksektir.

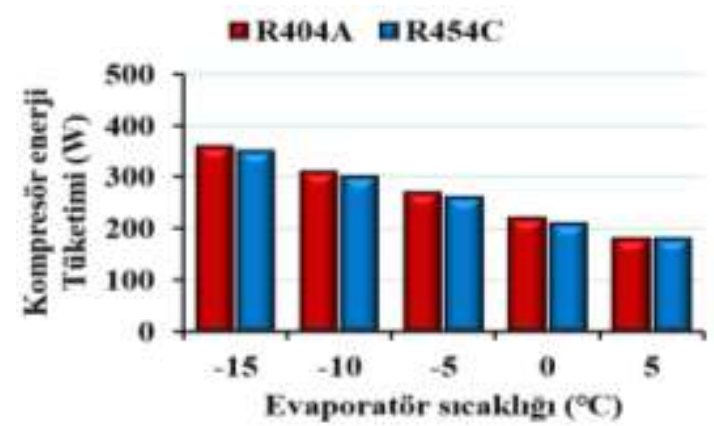

Şekil 4. Soğutucu akışkanların kompresör enerji tüketimlerinin karşılaștırılması

Soğutucu akışkanların COP değerlerinin karşılaştırılması Şekil 5'te verilmiştir. R404A'nın COP değeri 2.74 ile 5.46 arasında değişirken, R454C'nin COP değeri 2.88 ile 5.65 arasında değişmektedir. R454C'nin COP değeri R404A'dan yaklaşık olarak $\% 4.0$ oranında daha yüksektir.

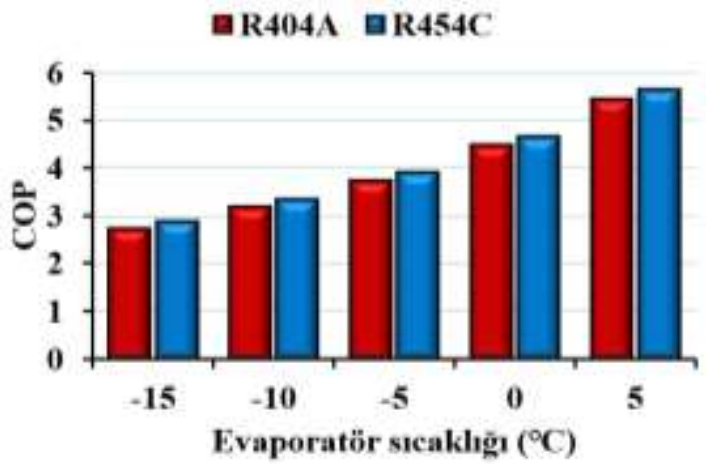

Şekil 5. Soğutucu akışkanların COP değerlerinin karşılaştırılması

\section{2. Çevresel Analiz Sonuçları}

Soğutucu akışkanların LCCP analizi Şekil 6'da görülmektedir. R404A'nın LCCP değeri $24740 \mathrm{kgCO}_{2}$ ile $12370 \mathrm{kgCO}_{2}$ arasında değişirken, R454C'nin LCCP değeri $24053 \mathrm{kgCO}_{2}$ ile $12370 \quad \mathrm{kgCO}_{2}$ arasında değişmektedir. Şekil 5'te görüldüğü gibi R454C'nin LCCP değeri R404A'dan biraz düşüktür (yaklaşık \%3.5). Buradan da anlașllacağı üzere buhar sıkıștırılmalı sistemlerin toplam emisyonlarının azaltılması için sadece GWP oranı düşük soğutucu akışkanların kullanılması veya soğutucu akışkan şarj miktarının azaltılması yeterli değildir. Çünkü bunlar sadece buhar sıkıștırmalı sistemlerin direkt emisyonlarını azaltır. Ancak yukarıda da açıklandığı gibi buhar sıkıştırmalı sistemlerin LCCP analizinde en çok emisyonlar enerji tüketiminden kaynaklanmaktadır. Bu yüzden buhar sıkıştırmalı sistemlerinin verimleri arttırılmalı ve bu sistemler için gerekli olan elektrik enerjisinin yenilenebilir enerji kaynaklarından üretilmesi gerekir.

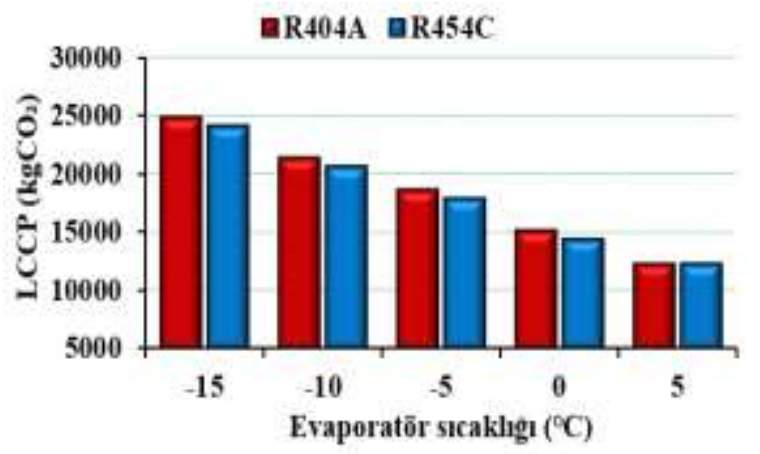

Şekil 6. Soğutucu akışkanların LCCP analizinin karşılaştırılması

\section{Tartışma ve Sonuç}

Bu çalışmada, soğutma siteminde R404A ya alternatif olan düşük GWP oranına sahip R454C soğutucu akışkanlarının enerji ve çevresel analizi yapılmıştır. Çalışmadan elde edilen sonuçlar aşağıda verilmiştir:

- R404A'nın soğutucu akışkan debisi R454C'den yüksektir (yaklaşık \%18.50). Bunun nedeni R404A'nın yoğunluğu R454C'den yüksek olmasından dolayıdır.

- R404A'nin kompresör enerji tüketimi R454C'den \%2.8 ile \%4.5 oranında daha yüksektir.

- R454C'nin COP değeri R404A'dan yaklaşık olarak \%4.0 oranında daha yüksektir.

- R454C'nin LCCP değeri R404A'dan biraz düşüktür (yaklaşık \%3.5).

\section{Kaynakça}

[1] "Regulation (EU) No 517/2014 of the European Parliament and of the Council of 16 April 2014 on fluorinated greenhouse gases and repealing Regulation (EC) No 842/2006 European Environment Agency." [Online]. Available: https://www.eea.europa.eu/policydocuments/regulation-eu-no-517-2014. [Accessed: 21-May-2021].

[2] Llopis, R., Calleja-Anta, D., Sánchez, D., NebotAndrés, L., Catalán-Gil, J., Cabello, R. 2019. R454C, R-459B, R-457A and R-455A as lowGWP replacements of R-404A: Experimental evaluation and optimization. International Journal of Refrigeration, 106, 133-143.

[3] Poggi, F., Macchi-Tejeda, H., Leducq, D., Bontemps, A. 2008. Refrigerant charge in refrigerating systems and strategies of charge reduction. International Journal of Refrigeration, 31, 3, 353-370.

[4] Mendoza-Miranda, J. M., Mota-Babiloni, A., 
Navarro-Esbrí, J. 2016. Evaluation of R448A and R450A as low-GWP alternatives for R404A and R134a using a micro-fin tube evaporator model. Applied Thermal Engineering, 98, 330339.

[5] Li G. 2017. Comprehensive investigation of transport refrigeration life cycle climate performance. Sustainable Energy Technologies and Assessments, 21, 33-49.

[6] Kumaş, K., Akyüz, A. 2020. Performance Analysis of R450A Refrigerant in Vapor Compression Cooling System for Sustainable Environment. Akademia Doğa ve İnsan Bilimleri Dergisi, 6, 1, 57-71.

[7] Dincer İ. and Kanoğlu M., Refrigeration systems and applications, Second. United Kingdom: Wiley, 2010.

[8] Çengel Y. A., Boles M. A., 2008. Termodinamik: mühendislik yaklaşımıyla. İzmir: İzmir Güven Kitabevi.

[9] Yıldız A., Yıldırım R. 2021. Investigation of using R134a, R1234yf and R513A as refrigerant in a heat pump. International Journal of Environmental Science and Technology, 18, 3, 1201-1210.

[10] Choi, S., Oh, J., Hwang, Y., Lee, H. 2017.“Life cycle climate performance evaluation (LCCP) on cooling and heating systems in South Korea. Applied Thermal Engineering, 120, 88-98.

[11] Yıldız A., Ylldırım, R. 2020. Energy and Environmental Analysis of Vapor Compression Refrigeration Systems Using an Alternative Refrigerant (R513A) to R134a, Duzce University Journal of Science and Technology, 8, 3, 1817-1828.

[12] Aprea, C., Greco, A., Maiorino, A. 2018. HFOs and their binary mixtures with HFC134a working as drop-in refrigerant in a household refrigerator: Energy analysis and environmental impact assessment. Applied Thermal Engineering, 141, 226-233.

[13] Atilgan, B., Azapagic, A. 2016. Assessing the Environmental Sustainability of Electricity Generation in Turkey on a Life Cycle Basis. Energies, 9, 1, 31. 